\title{
Evolution, divergence and loss of the Nodal signalling pathway: new data and a synthesis across the Bilateria
}

\author{
CRISTINA GRANDE*,1, JOSÉ MARÍA MARTÍN-DURÁN², NATHAN J. KENNY 3,\#, MARTA TRUCHADO-GARCÍA \\ and ANDREAS HEJNOL ${ }^{2}$
}

\begin{abstract}
'Departamento de Biología Molecular and Centro de Biología Molecular "Severo Ochoa" (Consejo Superior de Investigaciones Científicas - Universidad Autónoma de Madrid), Madrid, Spain, ${ }^{2}$ Sars International Centre for Marine Molecular Biology, University of Bergen, Bergen, Norway and ${ }^{3}$ Evolution and Development Research Group, Department of Zoology, University of Oxford, UK
\end{abstract}

\begin{abstract}
Since the discovery that the TGF- $\beta$ signalling molecule Nodal and its downstream effector Pitx have a parallel role in establishing asymmetry between molluscs and deuterostomes the debate over the degree to which this signalling pathway is conserved across the Bilateria as a whole has been ongoing. Further taxon sampling is critical to understand the evolution and divergence of this signalling pathway in animals. Using genome and transcriptome mining we confirmed the presence of nodal and Pitx in a range of additional animal taxa for which their presence has not yet been described. In situ hybridization was used to show the embryonic expression of these genes in brachiopods and planarians. We show that both nodal and Pitx genes are broadly conserved across the Spiralia, and nodal likely appeared in the Bilaterian stem lineage after the divergence of the Acoelomorpha. Furthermore, both nodal and Pitx mRNA appears to be expressed in an asymmetric fashion in the brachiopod Terebratalia transversa. No evidence for the presence of a Lefty ortholog could be found in the non-deuterostome genomic resources examined. Nodal expression is asymmetric in a number of spiralian lineages, indicating a possible ancestral role of the Nodal/ Pitx cascade in the establishment of asymmetries across the Bilateria.
\end{abstract}

KEY WORDS: Nodal, Pitx, Spiralia, Bilateria, Brachiopoda

\section{Introduction}

Nodal is a transforming growth factor- $\beta$ (TGF- $\beta$ ) ligand that has a critical role in establishing communication among individual cells and is involved in cell differentiation and development. Nodal signals can act as morphogens and are essential at key moments and distinct tissues throughout development to determine primary body axes, ensure proper gastrulation and neural patterning, cardiogenesis, and the maintenance of embryonic stem cell pluripotency (reviewed in Shen 2007; Schier 2009; Quail et al., 2013). The regulation of the Nodal pathway involves a complex network of receptors, coreceptors, antagonists and intracellular proteins, as well as positive and negative feedback loops that together define cell proliferation, differentiation, and tissue morphogenesis. The Nodal pathway is mainly restricted to embryonic and reproductive cell types and rarely activated during later development and adulthood although recent evidence suggests that this pathway is up-regulated during cancer progression (Lawrence et al., 2011; Lee et al., 2010; Lonardo et al., 2011; Strizzi et al., 2012; Topczewska et al., 2006).

Nodal, like most TGF- $\beta$ ligands, is synthesized as a pro-peptide that is cleaved in the secretory pathway into an amino-terminal pro-domain and a carboxy-terminal fragment that constitutes the mature form. This cleavage, together with dimerization, is essential to form an active ligand that can bind to a specific pair of receptor serine/threonine kinases, known as receptor types I and II (Shen 2007). The formation of this ligand/receptor complex brings together two type I and two type II receptors, allowing the phosphorylation and subsequent activation of Receptor I by Receptor II. While receptor type II kinases are constitutively active, type I receptors

Abbreviations used in this paper: AP, anterior posterior; LR, left right; TGF- $\beta$, transforming growth factor- $\beta$.

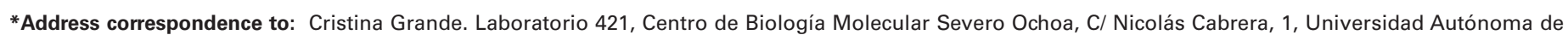
Madrid, E-28049 Madrid, Spain. Tel: +34-91-196-4703. e-mail: cgrande@cbm.csic.es

\#Present address: School of Life Sciences, Chinese University of Hong Kong, Shatin, Hong Kong
}

Supplementary Material (2 figures and 2 tables) for this paper is available at: http://dx.doi.org/10.1387/ijdb.140133cg

Accepted: 18 September 2014.

ISSN: Online 1696-3547, Print 0214-6282

(C) 2014 UBC Press

Printed in Spain 
require the formation of a ligand/receptor complex for this activation. Upon activation, the ligand/receptor complex is internalized by endocytotic mechanisms. Once in the cytoplasm, the Receptor I phosphorylates Smad2/3 proteins that propagate signalling through their binding to Smad4 proteins, nuclear translocation and regulation of gene expression (see reviews in Shen 2007; Massagué 2012; Xu et al., 2012).

Despite its apparent simplicity, this pathway can, however, produce highly complex patterns of target gene expression and diverse downstream effects, which can even be antagonistic in some cases. Recent studies have shown the relevance of the regulation of the signal transduction and transcription, and the epigenetic status of the cell in shaping the TGF- $\beta$-mediated transcriptional response in a cell (Massagué 2012). Hence, cell response to Nodal signalling depends on the cell context, defined by the levels of ligand/receptor complexes, the receptor activity, the activity of Smad proteins, and Smad accumulation in the nucleus, as well as by the presence of other transcription factors, histone readers, modifiers and chromatin remodellers that determine which genes will be targeted (Massagué 2012).

nodal was first identified in studies of mouse embryogenesis (Zhou et al., 1993) and subsequent description and functional characterization of nodal homologs during early chick, frog, and zebrafish embryogenesis corroborated data from mouse (reviewed in Tian and Meng 2006). Hence, all vertebrates have in common: first, that the onset of nodal expression is zygotic; second, that the expression is restricted to mesodermal precursors before gastrulation and to the site of gastrulation in all three germ layers during gastrulation; and third, that nodal is involved in the early specification of mesoderm and endoderm as well as anterior posterior (AP) and left right (LR) axis specification (Schier and Shen 2000; Wlizla 2011). Although many similarities were identified in the core of the Nodal pathway across different vertebrate groups, the downstream targets have been found to differ between taxa. The nodal gene itself, another TGF- $\beta$ ligand called lefty and the transcription factor Pitx2 have been shown to be the only direct target genes of Nodal signalling that are shared by all vertebrates (Schier 2009). The activation of Pitx2 in the left mesoderm by Nodal and the role of Lefty in regulating this process is a conserved cascade that determines mesoderm specification and LR determination in all vertebrates.

In addition, nodal, lefty, and Pitx orthologs have also been characterized in non-vertebrate deuterostomes (Morokuma et al., 2002; Yu et al., 2002; Duboc et al., 2005; Wlizla 2011). Comparative studies on cephalochordates, urochordates, hemichordates and echinoderms have shown that in these species, as in vertebrates, Nodal signalling is necessary to establish the polarity of the embryo, (i.e. LR asymmetry and the oral-aboral and AP axes). However, unlike vertebrate nodal, which is expressed in the endomesoderm and is involved in its induction, non-vertebrate deuterostome nodal is expressed in different germ layer precursors depending on the group, and does not play a broad role in endoderm and mesoderm specification in all groups. Especially intriguing are results in echinoderms, since nodal and Pitx are expressed in the ectoderm and endoderm (Duboc et al., 2010; Ohguro et al., 2011; Bessodes et al., 2012), and mesoderm cells are specified even when the pathway is blocked (Duboc et al., 2005). In addition, as mentioned above, asymmetric expression and the actions of the Nodal pathway are conserved features of deuterostomes. However, nodal and Pitx act on the right side in echinoderms and hemichordates (grouped together in the Ambulacraria) but on the left side of the chordate embryos (cephalochordates, urochordates and vertebrates) (Hamada et al., 2002; Morokuma et al., 2002; Yu et al., 2002; Duboc et al., 2005; Wlizla, 2011). These differences have hampered the inference of the ancestral expression domains and roles of the Nodal signalling pathway in deuterostomes, as most phylogenetic evidence suggests a sister group relationship between the Chordata and Ambulacraria (see Fig 4).

Together with deuterostomes, ecdysozoans (including arthropods and nematodes, among others), chaetognaths and spiralians (including, for example, snails and brachiopods) are the main lineages of the Bilateria. Ecdysozoans, chaetognaths and spiralians are more closely related to each other than to deuterostomes, together forming the Protostomia (Aguinaldo et al., 1997; Halanych 2004; Dunn et al., 2008). In addition, recent morphological and molecular data support Acoelomorpha and Xenoturbella as sister group to all remaining bilaterians (Hejnol et al., 2009). The absence of nodal and lefty orthologs in the genomes of Drosophila and C. elegans suggested that Nodal signalling was absent from ecdysozoans and initially led to the general understanding that the Nodal pathway was restricted to deuterostomes. Recently, however, a nodal ortholog was described in snails (Grande and Patel 2009), suggesting a new scenario where Nodal signalling evolved before the bilaterians split into the Ecdysozoa, the Chaetognatha, the Spiralia and the Deuterostomia (Grande and Patel 2010).

Outside deuterostomes, Nodal signalling has only been investigated in snails with two different types of body handedness: dextral (right-handed) and sinistral (left-handed) coiling (Grande and Patel 2009; Kuroda et al., 2009). These two forms of body organization are a manifestation of LR asymmetry in snails. A maternal effect locus determines the handedness of the third division in the typical spiral cleavage in snails and consequently adult handedness (Boycott and Diver 1923; Sturtevant 1923; Boycott et al., 1930; Freeman and Lundelius 1982). Hence, a dextral third cleavage will correspond to a right-handed adult and a sinistral third cleavage to a left-handed adult. Interestingly, nodaland Pitxare asymmetrically expressed and regulate LR asymmetries in snails as they do in deuterostomes (Grande and Patel 2009). However, the side of the embryo that expresses these genes is related to body handedness: nodal and Pitx are expressed on the right ectoderm of the dextral species and on the left in the sinistral species. Mechanical micromanipulation of the third cleavage chirality leads to reversal of embryonic nodalexpression patterns and reversal of embryonic and adult handedness (Kuroda et al., 2009). Although some evidence indicates that the last common ancestor of all snails had a dextral body handedness (Ponder and Lindberg 1997) the presence of both left and right-hand sided nodal expression means that the ancestral pattern in the Mollusca could not be inferred without other evidence from the Spiralia.

Altogether, this evidence shows that Nodal signalling arose in the lineage leading to the last common ancestor of ecdysozoans, chaetognaths, spiralians, and deuterostomes. However, the pathway has been only described in deuterostomes and snails, and the findings clearly highlight the need for further investigation in other taxa to understand the evolutionary history of the pathway. To gain new insights into the origin and evolution of Nodal signalling in the Bilateria, we have investigated the presence of nodal, lefty and Pitx gene orthologs in different groups of bilaterally symmetrical organisms. By surveying the genomic/transcriptomic resources 


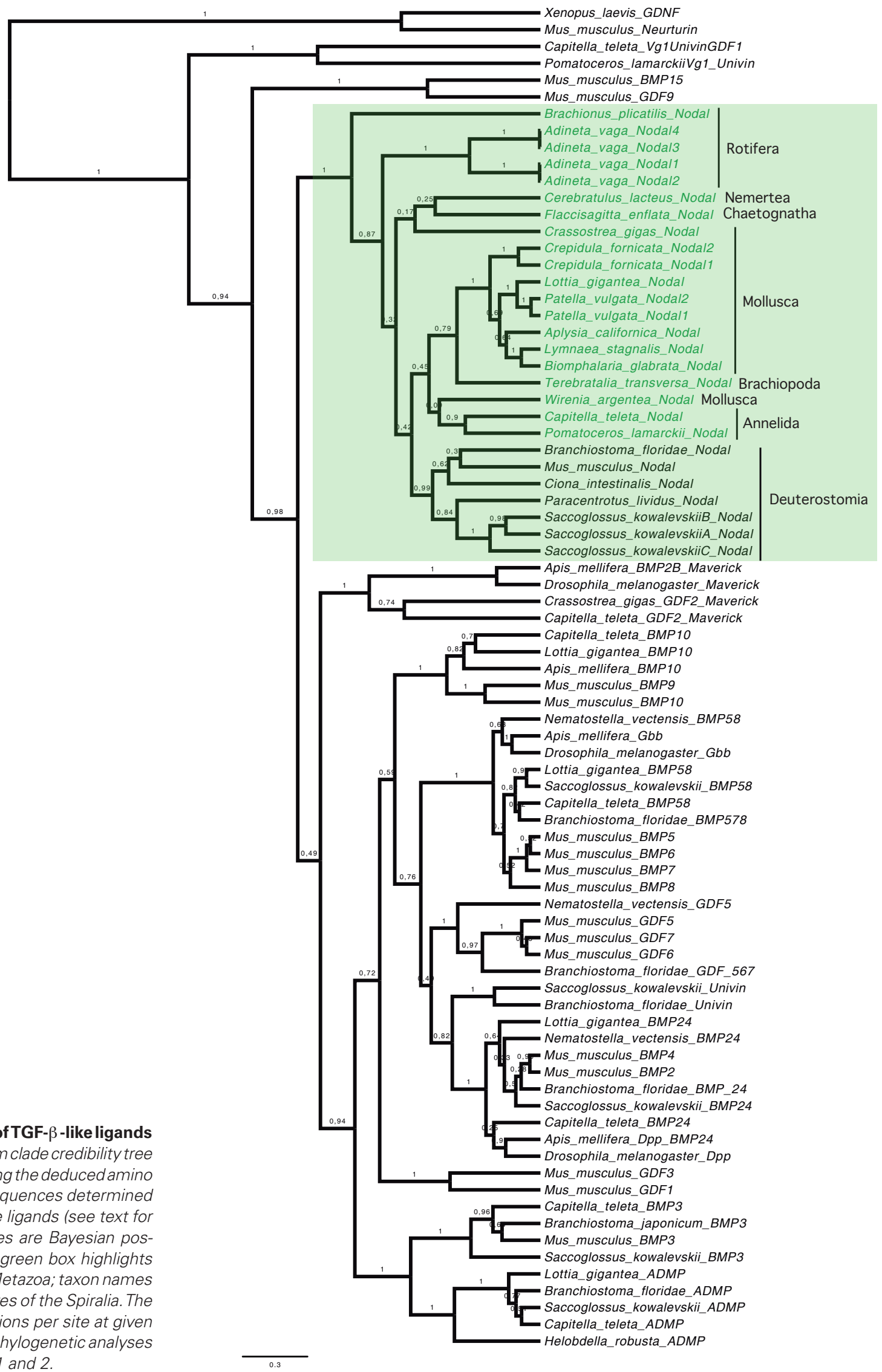

Fig. 1. Phylogenetic analysis of TGF- $\beta$-like ligands across the Metazoa. Maximum clade credibility tree from the Beast analysis including the deduced amino acid sequences of all Nodal sequences determined so far together with TGF- $\beta$-like ligands (see text for details). Numbers above nodes are Bayesian posterior probabilities (BPP). The green box highlights Nodal sequences across the Metazoa; taxon names in green indicate representatives of the Spiralia. The scale bar represents substitutions per site at given distance. Sequences used in phylogenetic analyses can be found in Supp. Tables 1 and 2 .

Xenopus laevis GDNF

Mus_musculus_Neurturin

Capitella_teleta_Vg1UnivinGDF1

ParckiiVg1 Univin

Adineta vaga Nodal4

Adineta_vaga_Nodal3

Adineta_vaga_Nodall

Nodal Nemertea

Patella vulgata Nodal

Brachiopoda

Deuterostomia 
available for representatives of different metazoan groups, as well as by direct amplification and sequencing, we show the existence of nodal and Pitx orthologs in several bilaterians, including rotifers, brachiopods, nemerteans, and chaetognaths. In addition, we have investigated the expression pattern of nodal and Pitx in the brachiopod Terebratalia transversa as well as that of Pitx in the embryos of the planarian Schmidtea polychroa, representing key taxa for further understanding of this cascade in the spiralian clade. With this new data incorporated, we have reviewed our present knowledge on Nodal signalling and interpreted it in an evolutionary context, providing strong confirmation of an ancestrally shared role for the Nodal pathway in establishing LR asymmetry, expressed on the right hand side of the body, and present before the divergence of the spiralia and deuterostome lineages from their common ancestor.

\section{Results}

\section{Nodal in Bilateria}

We searched the genomes and transcriptomes of representatives of several metazoan lineages to identify Nodal orthologs (Supp. Table 1). Furthermore, we used degenerate PCR in several species for which genomic or transcriptomic information was not available to complete our catalogue of nodal orthologs. We performed a phylogenetic analysis, including the newly determined amino acid sequences of Nodal, along with previously reported Nodal and

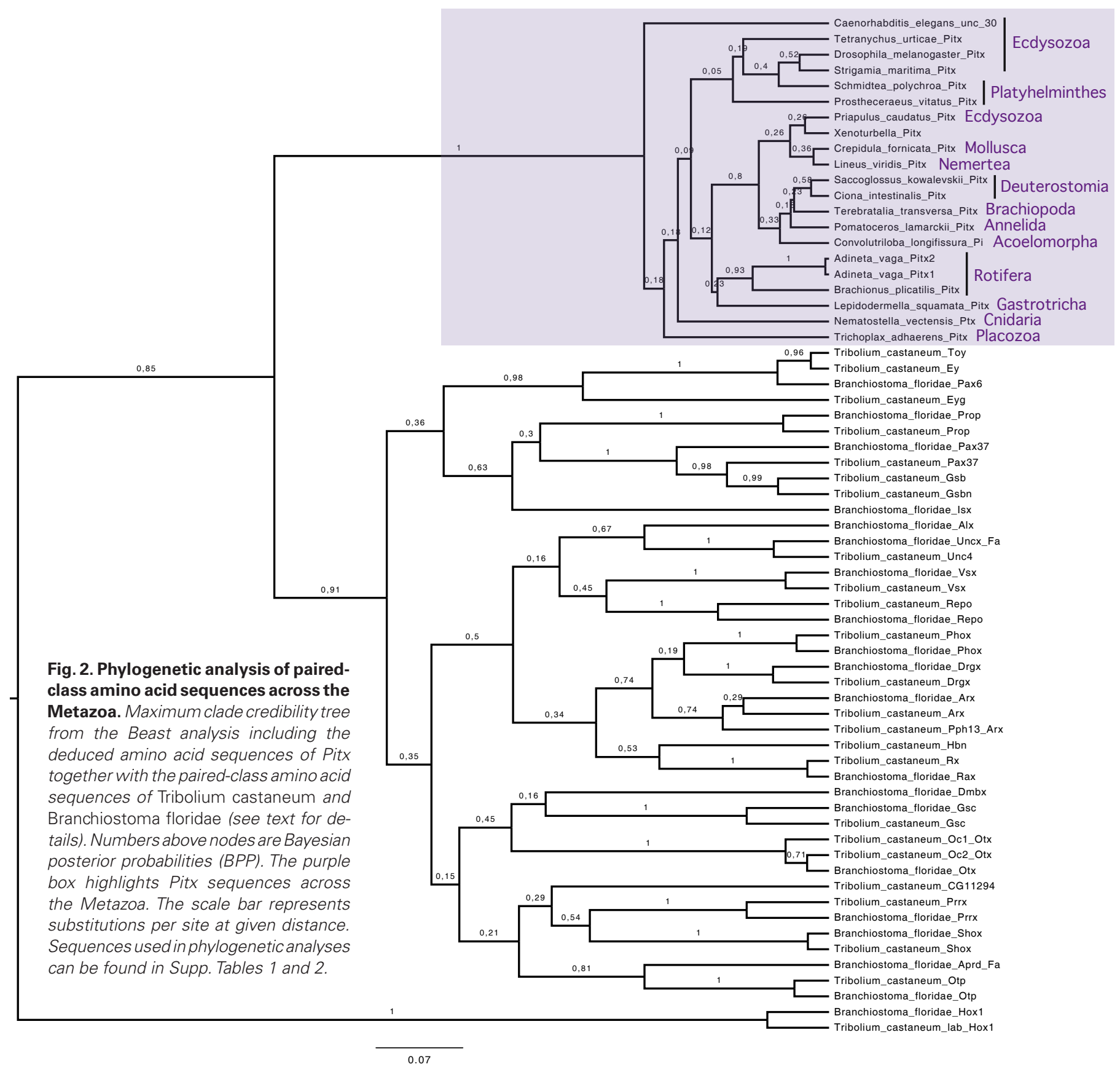


TGF- $\beta$ sequences of other spiralians and deuterostomes from GenBank (Supp. Table 1, Supp. Table 2 and Supp. Fig. 1). The resulting tree confirmed with high statistical support that the newly identified Nodal sequences were indeed more closely related to the previously reported Nodal sequences than to any other TGF$\beta$ sequences. Candidate sequences were identified as orthologs when they clustered with high statistical support (BPP>0.9) with sequences of known identity. Based on this criterion, our analysis shows that a Nodal homolog protein is present in several bilaterian taxa besides deuterostomes and snails (Fig. 1).

We did not identify any potential nodal ortholog gene in the genomes or RNA-seq datasets of any acoelomorph or Xenoturbella, which have been proposed to be the sister group to all remaining Bilateria (Supp. Table 1). Blast searches were performed on the genomic datasets of several ecdysozoans without a positive identification of nodal (Supp. Table 1). In addition, searches in both the RNA-seq dataset for the ecdysozoan priapulid Priapulus caudatus and direct amplification with degenerate primers for nodal in this species did not provide any potential nodal ortholog for this group (Supp. Table 1).

We also sought nodal ortholog genes in several spiralians with a variety of results (Supp. Table 1). Genomic and RNA-seq datasets, as well as direct amplification with degenerate primers for nodal, were used to identify a potential nodal ortholog in the rotifers Adineta vaga and Brachionus plicatilis, the annelids Capitella teleta and Pomatoceros lamarckii, the molluscs Patella vulgata, Crepidula fornicata, and Wirenia argentea, the brachiopod T. transversa, and the nemertean Cerebratulus lacteus. However, genomic, RNA-seq data, and direct amplification with degenerate primers did not retrieve any potential nodal ortholog for the platyhelminthes Schmidtea mediterranea, S. polychroa, Macrostomum lignano, Prostheceraeus vittatus, Prosthiostomum siphunculus, Stenostomum sthenum, and Schistosoma mansoni, the gastrotrich Lepidodermella squamata, the cycliophore Symbion pandora, or the bryozoans Bugula neritina and Membranipora membranacea (Supp. Table 1). Finally, degenerate primers for noda/were used to identify a potential nodal ortholog in the chaetognath Flaccisagitta enflata (Supp. Table 1).

When present, a single copy of nodalgene was detected in most groups, except for the bdelloid rotifer $A$. vaga, where four copies were identified, and the gastropods $P$. vulgata and $C$. fornicata, where two copies were retrieved. A detailed analysis of Nodal sequences across groups showed that while the amino-terminal pro-peptide was highly variable, the carboxy-terminal was highly conserved, and contains the seven cysteine residues previously described as can be seen in positions 1, 30, 34, 62, 63, 99 and 101 of our alignment (Supp. Fig. 1).

\section{Pitx in Bilateria}

We also looked for Pitx orthologs in several metazoan lineages (Supp. Table 1). Genomic and RNA-seq datasets, as well as direct amplification with degenerate primers for Pitx were used to identify potential Pitx orthologs in the priapulid P. caudatus, Xenoturbella bocki, the chaetognath F. enflata, the gastrotrich $L$. squamata, the platyhelminthes $S$. polychroa and $P$. vittatus, the rotifers $A$. vaga and $B$. plicatilis, the annelid $P$. lamarckii, the molluscs $P$. vulgata and $C$. fornicata, the brachiopod $T$. transversa and the nemertean Lineus viridis. Two copies of Pitx were detected in the bdelloid rotifer $A$. vaga.
Phylogenetic analyses included the newly determined amino acid sequences of Pitx together with previously reported Pitx and paired-class sequences of other bilaterians and non-bilaterian metazoans available from GenBank (Supp. Table 1 and Supp. Table 2). The resulting tree confirmed with high statistical support the identity of these new sequences of Pitx (Fig. 2).

\section{Expression patterns of nodal and Pitx in T. transversa}

We have characterized the RNA expression patterns of nodal and Pitx in the brachiopod T. transversa. Following fertilization, brachiopod embryos undergo radial cleavage, gastrulation by invagination, and the formation of a planktonic larva, which finally settles to metamorphose into the adult. We did not detect any nodal or Pitx signals before the larval stages. During early and late larval stages, there is just one domain of nodal expression, in the mesoderm on the right side of the embryo (Fig. 3A, a, c, e, and g). In early larvae, Pitx expression is detected in the anterior mesoderm on both sides of the embryo, although it is clearly stronger on the right side (Fig. 3A, b and d). Two additional Pitx expression domains are detected in late larval stages: one symmetrical in the mesoderm of the mantle lobe and one asymmetrical in the mesoderm of the right side (Fig. $3 \mathrm{~A} f$ and $h$ ). Embryos of T. transversa double-labelled for nodal and Pitx show that these expression domains are not co-localized (Fig. 3B).

\section{Discussion}

\section{Tracing the origin of the Nodal pathway}

The Nodal pathway has attracted much attention because of its critical role in deuterostome development. In particular, Nodal signalling is known to regulate gastrulation and the proper segregation of the germ layers in key model species, and helps to establish the AP and LR axes in embryos. Therefore, understanding the multifunctional nature of the pathway and its relevance in morphological variation will help in the interpretation of morphological diversification during the evolution of bilaterians.

Our work suggests that the Nodal pathway evolved early in bilaterian evolution, with the core genes nodal and Pitx present in deuterostomes, spiralians and chaetognaths (Fig. 4). Searches in the genomic and RNA-seq datasets of Xenoturbella and Acoelomorpha as well as direct amplification in acoelomorphs have not revealed any nodal ortholog. Acoelomorphs and $X$. bocki are possibly the sister groups to the Bilateria as a whole (Hejnol et al., 2009, Srivastava et al., 2014), although alternative placements have been proposed, notably as a sister group to echinoderms+hemichordates or sister to all remaining deuterostomes (Phillipe et al., 2011) (Fig. 4). However, a newer phylogenomic analysis could not recover the result of Philippe et al., 2011, instead it confirms the Acoelomorpha as earliest split from the remaining Bilateria (Srivastava et al., 2014). Acoelomorphs and $X$. bocki share some ultrastructural features, including morphological characters in the digestive and nervous systems as well as a similar mode of development (Hejnol et al., 2009; Nakano et al., 2013). The fact that so far no LR morphological asymmetries have been described in either of these two groups and that no nodal ortholog has been identified in any of them may suggest that the last common ancestor of all bilaterians was morphologically symmetrical in the left-right axis. After acoelomorphs and Xenoturbella split from the bilaterian stem lineage, a duplicated TGF- $\beta$ family member gave rise to Nodal in 
the bilaterian stem species, which later evolved to regulate LR specification. The alternative placement of acoelomorphs and Xenoturbella as a sister group to Ambulacraria and the absence of Nodal in these species would otherwise imply the loss of Nodal and its role in establishing asymmetries in these species. A broader picture of TGF- $\beta$ ligand inter-relationships can be seen in other investigations, for example, Herpin et al., 2004 and Pang et al., 2011, where evidence from a range of basal metazoans is presented, and Kenny et al., 2014 in this issue where the TGF- $\beta$ signalling cassette of a range of spiralians are described in detail.

Within Spiralia, the presence of a nodal ortholog has been confirmed in molluscs (gastropods, bivalves, and neomeniomorphs), annelids, rotifers, brachiopods and nemerteans (Fig. 4). However, this gene could potentially be present in other groups such as bryozoans, gastrotrichs, gnathostomulids, cycliophorans and entoprocts. Unfortunately, genomic information for most of these groups is currently absent. Filling these gaps is key for a full understanding of the evolutionary history of this pathway.

Platyhelminthes, or at least those examined to date (catenulids, macrostomids, cestodes, triclads, and polyclads), seem to have lost the gene that encodes for Nodal. Morphological studies of platyhelminth embryos and adults have described perfect symmetric conformations along the bilateral axis and only rhabdocoel turbelarians show detectable asymmetries of the reproductive system (Grande 2010). Most free living platyhelminthes have male and female reproductive systems distributed symmetrically on both sides of the body. However, through the evolutionary history of rhabdocoels, the female reproductive system has been reduced on the left side and it is therefore located exclusively on the right side. In parallel, the male reproductive system has been reduced on the right side and it is therefore located on the left. Therefore, a search for the presence or absence of a nodal ortholog in this particular group of plathyhelminthes deserves special attention. If Nodal is absent in this group, a new, Nodal-independent mechanism for generating asymmetries in spiralians may be uncovered.

Interestingly, the nodalgene is present in chaetognaths. The sister-group relationship between chaetognaths and the remaining bilaterians has been under debate for decades. Chaetognaths have been related to deuterostomes (Ghirardelli 1981; Brusca and Brusca 2002), ecdysozoans (Littlewood et al., 1998;Zrzavy etal., 1998; Peterson and Eernisse 2001), spiralians (Matus et al., 2006) and as sister taxon to Spiralia + Ecdysozoa (Giribet et al., 2000; Helfenbein and Boore 2004; Marletaz etal., 2006; Nesnidal et al., 2013). However, new molecular and morphological evidence has supported their phylogenetic position as an independent lineage in the protostomes beside ecdysozoans and spiralians (Dunn et al., 2008). Chaetognaths have retained ancestral genomic features, such as the conservation of certain genes like that encoding for the Guanidinoacetate N-methyltransferase (GAMT) enzyme, and at the same time, have acquired some derived features, such as a trans-splicing mechanism of mRNA processing (shared with many other organisms, including several spiralians). This makes them a key group for understanding early evolutionary events in the Bilateria (Marletaz et al., 2008; Harzsch and Müller 2007; Harzsch et al., 2009; Harzsch and Wanninger 2010; Rieger et al., 2010). Further studies on the expression patterns and function of Nodal in this group will be particularly useful to understand the early role
Fig. 3. Expression of nodal and Pitx in brachiopod embryos. (A) Single colorimetric in situ hybridization fornodal and Pitx in the brachiopod T. transversa. nodal and Pitx are first detected in the early larva $(a-d)$. At this stage, nodal is expressed in a subset of the anterior right mesoderm adjacent to the nodal expression domain (light blue arrowhead in b). As the larva matures, noda is still detected in an anterior right mesodermal domain (green arrowhead in e,g), but Pitx is expressed in two ventral mesodermal domains and an asymmetric right dorsal domain (dark blue arrowhead in $f, h)$, in addition to the anterior-most mesodermal domain already observed in the early larva (light blue arrowhead in $f, h$ ). (B) Double fluorescent in situ hybridization for nodal and Pitx in early and late larva in T. transversa. The simultaneous detection of noda (green) and pitx (magenta) at these developmental stages demonstrates that their respective expression domains do not co-localize, but appear adjacent one to the other. In (A) panels e, $g$ and in (B) panels $I, m, n$, the red arrowhead indicates a region of probe trapping. $R$, right; $L$, left. 
of this pathway in protostomes.

Among deuterostomes, there is a single copy of the nodalgene in mammals, cephalochordates, urochordates, and echinoderms (Zhou et al., 1993; Morokuma et al., 2002; Yu et al., 2002; Duboc et al., 2004), whilst there are three copies in the hemichordate Saccoglossus kowalevskii (nodal A, B, and C) (Wlizla 2011), in zebrafish (Cyclops, Squint, and Southpaw) and six Nodal-related ligands in Xenopus (Xnr1-6) (Schier 2009). In spiralians, a single copy of nodal is present in all species examined to date, except the rotifer $A$. vaga and the gastropods $C$. fornicata and $P$. vulgata. $A$. vaga has four copies of the nodal gene, probably because the genomes of bdelloid rotifers show reduced tetraploidy (Flot et al., 2013). Less easy to explain is the presence of two copies of nodal in the two distantly related gastropods $C$. fornicata (Caenogastropoda) and $P$. vulgata (Patellogastropoda). The fact that one single copy has been identified so far in other gastropods like the patellogastropod Lottia gigantea and the heterobranchs Biomphalaria glabrata, Aplysia californica and Lymnaea stagnalis, along with a lack of clear paralogy in our tree (Fig. 1) might indicate that two independent duplication events could have occurred in $P$. vulgata and $C$. fornicata. Wider genomic sampling across gastropods is necessary to test this hypothesis.

\section{Ancestral expression domains and roles of Nodal}

Previous studies in vertebrates have shown that there is a Nodal concentration and duration-dependent effect in responding cells (Gurdon and Bourillot 2001; Schier and Talbot 2005; Hagos and Dougan 2007). Therefore, the timing and expression levels of nodal are tightly regulated. In deuterostomes as well as in snails, the nodal gene is activated during cleavage stages, where it is critical in regulating gastrulation (Chea et al., 2005; Grande and Patel 2009). However, the results presented here show that nodal is not active in brachiopods until larva stages, after gastrulation is complete and tissue layers are specified. Previously published data (e.g. Chea et al., 2005; Grande and Patel 2009) suggest that the early action of this gene and its function in the regulation of the

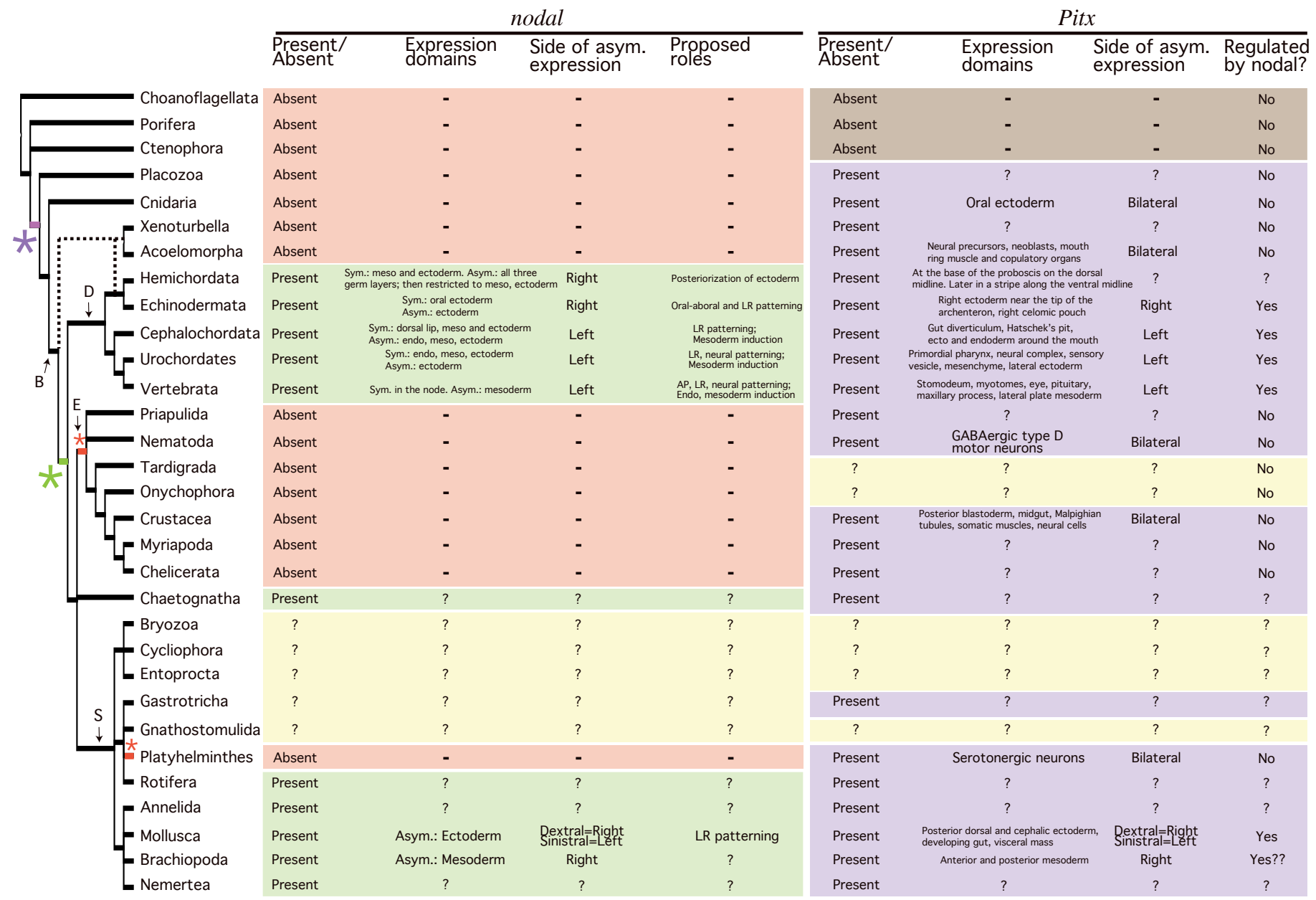

Fig. 4. Phylogenetic hypothesis of metazoan relationships and nodal and Pitx functions among Bilateria. For each Phylum, presence and absence, expression domains and side of the body that expresses nodal and Pitx are shown. Proposed roles for nodal and the relationship between nodal and Pitx are also indicated. Absent means not found in genomic or RNA-seq datasets. Question marks: no information available. Boldface dashes: gene not reported in the group. E: Ecdysozoa; B: Bilateria; S: Spiralia; D: Deuterostomia. Coloured asterisks represent the inferred origins of nodal (green) and Pitx (purple) and hypothesized nodal losses in Ecdysozoa and Platyhelmintha (red). Dotted lines represent two alternative phylogenetic hypotheses: 1) Acoelomorpha + Xenoturbella are sister to remaining Bilateria (Hejnol et al., 2009, Srivastava et al., 2014) and 2) Acoelomorpha + Xenoturbella are sister to Ambulacraria (Philippe et al., 2011). See text for details. 
gastrulation process may be the ancestral bilaterian condition. This implies that this has been secondarily modified in brachiopods, where nodal does not seem to have any role during gastrulation, and in those clades without a nodal gene (for example, in the Ecdysozoan lineage).

Inhibition of Nodal signalling causes disruption of germ layer induction of endoderm and mesoderm in vertebrates (Brennan et al., 2001; Vincent etal., 2003). However, current evidence suggests that this role is a vertebrate innovation, since normal specification has been reported in other deuterostomes (Duboc et al., 2004; Morokuma et al., 2002; Wlizla 2011), snails and brachiopods, as suggested by the late activation of nodal in the latter.

In addition, after gastrulation, nodal expression occurs in different germ layers depending on the group considered: the ectoderm in snails (Grande and Patel 2009), the ectoderm and endoderm in echinoderms (Duboc et al., 2010; Ohguro et al., 2011; Bessodes et al., 2012), all three germ layers in cephalochordates, urochordates, and hemichordates, and the endomesoderm in vertebrates (Hamada et al., 2002; Morokuma et al., 2002; Yu et al., 2002; Duboc et al., 2005; Wlizla 2011). Here we have shown that in brachiopods nodal is restricted to the mesoderm. These data suggest that the expression domains of nodal have greatly diverged during the evolution of bilaterians in parallel with the diversification of its roles. With the current data, hypotheses supporting that the ancestral state is either mesodermal, ectodermal or ectoendomesodermal are equally parsimonious and only additional data in other spiralians and chaetognaths is likely to shed light on this issue.

Comparative studies have shown that there are several different early symmetry-breaking mechanisms among the Bilateria (Spéder et al., 2007). However, in deuterostomes, snails and brachiopods, all these mechanisms converge in the asymmetric activation of Nodal signalling. While nodal expression in deuterostomes is initially symmetrical and depends on its own regulation in a positive and negative feedback loop to achieve an asymmetric pattern (Morokuma et al., 2002; Yu et al., 2002; Duboc et al., 2005), nodal expression in snails and brachiopods is asymmetric from the onset, and at least in snails, it does not seem to be regulated by its own expression (Grande and Patel 2009). Further studies are needed to elucidate the ways in which asymmetric expression of nodal is activated in different bilaterian taxa, and its subsequent regulation.

Interestingly, there is variation in the localization of the asymmetric expression of nodal and the subsequent tissue-specific laterality decisions among different groups. Nodal signalling acts on the left side in chordates (vertebrates, cephalochordates and urochordates, Boorman and Shimeld 2002; Chea et al., 2005; Morokuma et al., 2002; Yu et al., 2002) and on the right side in echinoderms and hemichordates, grouped together in the Ambulacraria, the sister group to the Chordata (Duboc and Lepage 2008). Hence, data from deuterostomes does not conclusively show the ancestral side of asymmetric expression domains, and additional data from outgroups is needed. Until now, the only nodal expression data on non-deuterostomes available was that from snails (Grande and Patel 2009). As previously explained, in snails the directionality of spiral cleavage at the third division defines the side of the embryo that expresses nodal and therefore the chirality of the adult snail. Right-handed spiral cleavage correlates with right-sided nodal expression and left-handed spiral cleavage correlates with leftsided nodal expression. It has been proposed that the ancestral snail had right-handed shell coiling (Ponder and Lindberg 1997) and therefore that the ancestral condition for snails was the expression of nodal on the right side of the embryo. The right-sided expression might be found in dextral snails or in spirally cleaving animals due to their mode of cleavage, rather than reflecting an ancestral bilaterian expression. Here, we show that the brachiopod T. transversa expresses nodal on the right side of its body, despite cleaving in a manner more akin to radial cleavage. This suggests that the right side expression of nodalis indeed the ancestral condition for spiralians and deuterostomes and that it was secondarily modified in the ancestor of all chordates.

The expression of nodal on the right body side in most animals outside the chordates has been used to support the hypothesis of inversion of the dorsoventral (DV) axis in the chordate lineage (Arendt and Nübler-Jung 1994; Denes et al., 2007). This inversion resulted in the illusion of a reversal of the left and right axis, although the site of nodalexpression within the body remained constant (for a more detailed explanation, see Namigai et al., 2014). The side that expresses nodal will differentiate and acquire new features when compared to the other side of the midline. While Nodal regulates 'leftness' in mouse embryos, as inappropriate induction of nodal activity on the right side produces left-side morphologies (Hamada et al., 2002), in echinoderms it regulates 'rightness' because Nodal signalling on the right side inhibits the formation of the rudiment in the larva (Duboc et al., 2005). Therefore the opposite sides of nodal expression may have profound implications for the roots of morphological evolution in bilaterians.

Besides gastrulation and LR determination, Nodal signalling has functional significance in the regulation of the AP and DV axes in vertebrates, urochordates, cephalochordates and hemichordates (Schier and Shen 2000; Wlizla 2011) as well as the oral-aboral axis in echinoderms (Duboc et al., 2004). By contrast, snails and brachiopods seem to define AP and DV axes independently of Nodal signalling, as these are defined in the former by the characteristics of spiralian cleavage, and in the latter, these axes are determined before the advent of nodal expression. Further studies in other spiralians as well as in chaetognaths will help to infer the ancestral role of the Nodal pathway in the polarization of embryos, and which roles are the result of independent co-option over evolutionary time.

\section{Downstream of Nodal: lefty and Pitx}

Although a variety of different transcriptional target genes of nodal have been reported in different deuterostome species, the TGF- $\beta$ family member lefty is a common target in all of them. Nodal induces lefty expression, which in turn restricts the duration and the site of Nodal influence. This antagonistic interaction constitutes an example of the reaction-diffusion theoretical model (Kondo and Miura 2010). Due to its relevance as a Nodal target gene as well as its critical role in regulating Nodal signalling, we decided to check for the presence of lefty orthologs in other bilaterians outside the Deuterostomia. In spite of our intensive searches, no lefty ortholog has been found in any representative outside deuterostomes although lefty can be easily recognised if present, as its distinct sequence, and lack of one cysteine residue, make it identifiable both in alignments and in phylogenetic analysis. Therefore, the current data suggest that Lefty originated and was incorporated as a key regulator of the Nodal pathway in the deuterostome stem lineage.

Nodal signals activate asymmetric Pitx expression in deuterostomes and snails (Ryan et al., 1998; Grande and Patel 2009), 
supporting the existence of the Nodal-Pitx cascade in the last common ancestor of deuterostomes, spiralians, ecdysozoans and chaetognaths (Fig. 4). Studies in deuterostomes and snails have shown that the asymmetric activation of Pitx is maintained once Nodal signals cease, and persists long enough to drive asymmetric organogenesis (Logan et al., 1998; Essner et al., 2000; Grande and Patel 2009). In addition to this asymmetric Nodal-dependent induction, Pitx is also detected in symmetric domains that persist even when Nodal function is down-regulated in both deuterostomes and snails. Therefore different, independent enhancers for Pitxwere likely present early in bilaterian evolution, each driving a portion of its expression. Here, we have shown that Pitx in T. transversa also has both symmetrical and asymmetrical expression domains. Although functional experiments have not yet been performed, the data presented here may suggest that the asymmetric expression domain of Pitx is regulated by Nodal signals in brachiopods as it is in other bilaterian species.

Our phylogenetic analysis confirms the existence of Pitx orthologs in the Placozoa and Cnidaria, as well as in several groups of bilaterians (Fig. 2). As previously discussed, platyhelminthes and ecdysozoans seem to have lost their nodal ortholog but they have retained a Pitx ortholog. Pitx expression data have been recently described in the adults of planarian platyhelminthes, where it is required for the maintenance and regeneration of serotonergic neurons as well as for proper midline patterning during regeneration (Currie and Pearson 2013). Accordingly, we have also found expression of Pitx in isolated neurons in the ventral side of the embryo of the planaria $S$. polychroa in a bilateral, symmetric fashion (Supp. Fig. 2). In addition, Pitx expression has been reported for the ecdysozoans $C$. elegans and Drosophila, and while no asymmetrical expression pattern has been reported, Pitx has been related to neuronal cell differentiation (McIntire et al., 1992; Vorbrüggen et al., 1997). Moreover, Pitx expression in acoelomorphs has been detected in neural precursors (Hejnol and Martindale 2009) and in neoblasts (Chiodin et al., 2013). In summary, current evidence supports the hypothesis that Pitx originated early outside the Bilateria, where it might have played a role in nervous cell differentiation. Once acoelomorphs and Xenoturbella split from the remaining bilaterians, Pitx acquired an additional role linked to the Nodal signalling pathway: regulation of LR patterning. Additionally, Pitx could have secondarily acquired a specific role in the regulation of the pituitary gland and its homologs in chordates (Boorman and Shimeld 2002).

\section{Conclusions}

Comparative developmental approaches are critical for understanding the evolution of animal form diversity. The variety of animal morphology has been shaped by a few signalling pathways, including Nodal signalling itself, that precisely regulate cell communication, division, migration, and death, among other mechanisms, throughout the evolution of metazoans. Recently, next generation sequencing techniques have allowed the production of genomic sequence data on non-model organisms at an unprecedented rate, greatly contributing to our knowledge of the diversity of signalling components across taxa and thus, to a more general understanding of their logic (Kenny et al., 2014, this issue). For many years, studies of the Nodal signalling pathway have focused mainly on deuterostomes, although new genomic information presented here has shown that this pathway has indeed a broader distribution across bilaterians. While roles in gastrulation, germ layer specification and AP and DV axis specification have been described in only a subset of bilaterian clades, Nodal signalling has a critical role in LR patterning in the few bilaterians examined, suggesting that the molecular mechanisms integrating positional information of the pathway along this axis could have been established early in the evolution of bilaterians. The phylogenetic distribution of the use of the Nodal pathway for establishing asymmetries however, suggest that spiralians and deuterostomes have convergently incorporated the Nodal pathway into their development for this purpose. Additional evidence from the Spiralia, however, corroborating a role for the entirety of the pathway in a manner consistent with an ancestrally shared role would suggest that the last common ancestor of these two groups had its asymmetry patterned by this mechanism. Evidence such as that presented in this paper is therefore vital for fully understand the evolution of this undoubtedly key signalling pathway.

Here, we have described the timing and specific domain of expression of nodal in brachiopods. We have shown that nodal and Pitx are asymmetrically activated in the right mesoderm of the developing larva, suggesting a potential role in the development of asymmetric features. Although no asymmetries have been described for extant brachiopod species so far, consistent asymmetric folding of the commissure is a characteristic feature of a small but significant number of brachiopod fossil species (Fürsich and Palmer 2007). It remains to be seen what the specific role asymmetric activation of nodal and Pitx performs in brachiopod development and morphogenesis, but it is possible that its function is related to asymmetries in the derivatives of the mesoderm of the mantle lobe.

To date, no nodalortholog has been detected in any representative of ecdysozoans or platyhelminthes. This evidence suggests that within bilaterians, the Nodal ligand has been independently lost in at least two lineages (Fig. 4). Further studies with more representatives of these groups will allow the dating of these losses. Organisms with morphological asymmetries but no Nodal ligand have to use different mechanisms to achieve their morphological asymmetries. For instance, actin and associated molecular motors such as myosins have been shown to be involved in LR determination in Drosophila (Spéder et al., 2006, 2007). In addition, ion pumps and ion channels have been proposed to actively transport small left-right determinants in only one direction in vertebrates (Levin et al., 2002) and could also be involved in early symmetry-breaking in nematodes (Huang et al., 2007). However, the universality of such mechanisms is a subject of some debate, and is nowhere near as scientifically established as the role of the Nodal/Pitx cascade in establishing asymmetry.

Finally, although the Nodal-Pitx cascade seems well conserved across the Bilateria with the obvious exception of the Ecdysozoa and Platyhelminthes, this does not seem to be the case for its regulators. While current data have shown that highly elaborate mechanisms control the regulation and the target genes of this pathway in examined model organisms in the Deuterostomia, our results show that the key regulator Lefty, which controls many aspects of this process, is a deuterostome novelty. This raises many questions as to the identity of regulators of this key pathway in other bilaterians, and, ultimately, the ancestral form of the ancestral regulatory cassette controlling this fundamental signalling cascade, which are sure to be the focus of future research. 


\section{Materials and Methods}

\section{Gene identification}

Potential nodal and Pitx orthologs were found in RNA-seq data, and complete genomic sources (Supp. Table1) using tBlastn (Altschul etal., 1990) with conserved regions of known gene homology. In addition, the nodalgene for the mollusc species $C$. fornicata and $W$. argentea, the annelid $P$. lamarckii, the chaetognath $F$. enflata and the nermertean $C$. lacteus were first amplified with degenerate primers (with sequences available from the authors on request). The SMARTer ${ }^{\mathrm{TM}}$ RACE kit (Clontech) was used to amplify longer 3 ' and 5' sequence. In addition, the Pitx gene for the chaetognath $F$. enflata was first amplified with degenerate primers, with sequences available from the authors on request. Translation into protein sequence was carried out using MacVector v12.7 (Olson 1994), assuming standard codon usage.

\section{Phylogenetic analyses}

Phylogenetic analyses included the newly determined amino acid sequences of Nodal, as well as the known Nodal sequences of other spiralians and deuterostomes and other TGF- $\beta$ superfamily members available from GenBank (Accession No. given in Supp. Table 2). In addition, the newly determined amino acid sequences of Pitx together with other Paired-class homeodomain containing genes of metazoans were subject to phylogenetic analysis (Supp. Table 2). Sequence alignments were visualized and aligned with Mesquite version 2.75 OSX (Maddison and Maddison 2011) and Clustal $X$ version 2.1 (Larkin et al., 2007). Conserved domains were identified and alignments trimmed to include only these areas for further analysis. Gene orthology was determined by phylogenetic analyses in BEAST v1.8.0 (Drummond et al., 2012). The optimal substitution model for each gene was selected with Prot-test v.2.4 (Abascal et al., 2005). In all cases, the best model selected was $\mathrm{LG}+\mathrm{I}+\mathrm{G}$ (Le and Gascuel 2008). For tree search, we used a birth-death prior under a strict clock model. The analyses were run for 20,000,000 generations and trees were sampled every 2,000 generations. Convergence of parameter estimates was visually checked in Tracer v1.5 (Rambaut and Drummond 2007). After a burn-in of $10 \%$, all values had effective sample sizes (ESSs) above 200, indicating good mixing. The post-burn-in samples of trees were summarized with TreeAnnotator v1.8.0, distributed as part of the BEAST package.

\section{Preparation and culture of embryonic material and whole mount in situ hybridization}

Gravid T. transversa adults were collected from the coast near Friday Harbor Laboratories (USA) during their reproductive season and spawned as described previously (Santagata et al., 2012). Embryos were collected at different stages of development up to the late larva stage. Fixation and in situ hybridization of embryos and larvae were performed following an established protocol (Passamaneck et al., 2011; Santagata et al., 2012). Planarian embryos were collected and in situ hybridization on these samples were performed as previously described (Martín-Durán et al., 2010). Stained embryos and larvae were imaged with a Zeiss Axiocam HRc connected to a Zeiss Axioscope Ax10 using bright field Nomarsky optics. All images were analyzed with Photoshop CS5 (Adobe).

\section{Acknowledgments}

Thanks to I. Martínez-Solano for helping in phylogenetic analysis and comments on the article. Thanks to Jonathan Henry and Christiane Todt for help with collecting embryos of $\mathrm{C}$. lacteus and W. argentea. CG is currently a "Ramon y Cajal" postdoctoral fellow supported by the Spanish MICINN and the UAM and funded by project CGL2011-29916 (MICINN). JMMD is supported by Marie Curie IntraEuropean (IEF) post-doctoral fellowship 329024. CG was funded by a YGGDRASIL Travel Fellowship from the Norwegian Research Council. MTG is supported by a predoctoral fellowship (Ref. BES2012-052214 MICINN). NJK was supported by Santander Academic Travel Award. We would like to thank two anonymous reviewers for improving this manuscript with their suggestions. Thanks to the editor of this special issue, Professor J.Q. Henry, for his helpful comments.

\section{References}

ABASCAL F, ZARDOYA R and POSADA D (2005). ProtTest: Selection of best-fit models of protein evolution. Bioinformatics 21: 2104-2105

AGUINALDO A M, TURBEVILLE J M, LINFORD L S, RIVERA M C, GAREY J R, RAFF R A and LAKE J A (1997). Evidence for a clade of nematodes, arthropods and other moulting animals. Nature 387: 489-493.

ALTSCHUL S F, GISH W, MILLER W, MYERS E W and LIPMAN D J (1990). Basic local alignment search tool. J Mol Biol 215: 403-410.

ARENDT D, NÜBLER-JUNG K (1994). Inversion of dorsoventral axis? Nature 371: 26.

BESSODES N, HAILLOT E, DUBOC V, RÖTTINGER E, LAHAYE F and LEPAGE T (2012). Reciprocal signaling between the ectoderm and a mesendodermal leftright organizer directs left-right determination in the sea urchin embryo. PLOS Genet 8: e1003121.

BOORMAN C J, SHIMELD S M (2002). Pitx homeobox genes in Ciona and amphioxus show left-right asymmetry is a conserved chordate character and define the ascidian adenohypophysis. Evol Dev 4: 354-365.

BOYCOTTAE, DIVER C (1923). On the inheritance of sinistrality in Limnaea peregra Proc $R$ Soc Lond B 95: 207

BOYCOTT A E, DIVER C, GARSTANG S L and TURNER F M (1930). The inheritance of sinistrality in Limnaea peregra (Mollusca: Pulmonata). Phil Trans $R$ Soc B 219: 51-131.

BRENNAN J, LU C C, NORRIS D P, RODRIGUEZ T A, BEDDINGTON R S and ROBERTSON E J (2001). Nodal signalling in the epiblast patterns the early mouse embryo. Nature 411: 965-969.

BRUSCA R C, BRUSCA G J (2002). Invertebrates (2nd ed.). Sunderland, Mass. Sinauer Associates.

CHEA H K, WRIGHT C V and SWALLA B J (2005). Nodal signaling and the evolution of deuterostome gastrulation. Dev Dyn 234: 269-278.

CHIODIN M, BØRVE A, BEREZIKOV E, LADURNER P, MARTINEZ P and HEJNOL A. (2013). Mesodermal gene expression in the acoel Isodiametra pulchra indicates a low number of mesodermal cell types and the endomesodermal origin of the gonads. PLoS ONE 8: e55499. doi:10.1371/journal.pone.0055499.

CURRIE K W, PEARSON B J (2013). Transcription factors Ihx1/5-1 and pitx are required for the maintenance and regeneration of serotonergic neurons in planarians. Development 140: 3577-3588.

DENES AS, JÉKELY G, STEINMETZP R, RAIBLE F, SNYMAN H, PRUD'HOMME B, FERRIER D E K, BALAVOINE G and ARENDT D (2007). Molecular architecture of annelid nerve cord supports common origin of nervous system centralization in Bilateria. Cell 129: 277-288.

DRUMMOND A J, SUCHARD M A, XIE D and RAMBAUT A (2012). Bayesian phylogenetics with BEAUti and the BEAST 1.7. Mol Biol Evol 29: 1969-1973.

DUBOC V, RÖTTINGER E, BESNARDEAU L and LEPAGE T (2004). Nodal and BMP2/4 signaling organizes the oral-aboral axis of the sea urchin embryo. Dev Cell 6: 397-410.

DUBOC V, RÖTTINGER E, LAPRAZ F, BESNARDEAU L and LEPAGE T (2005). Left-right asymmetry in the sea urchin embryo is regulated by Nodal signalling on the right side. Dev Cell 9: 147-158.

DUBOC V, LEPAGE T (2008). A conserved role for the nodal signalling pathway in the stablishment of dorso-ventral and left-right axes in deuterostomes. J Exp Zool B Mol Dev Evol 310: 41-53.

DUBOC V, LAPRAZ F, SAUDEMONT A, BESSODES N, MEKPOH F, HAILLOT E, QUIRIN $M$ and LEPAGE T (2010). Nodal and BMP2/4 pattern the mesoderm and endoderm during development of the sea urchin embryo. Development 137: 223-235

DUNN C W, HEJNOLA, MATUS D Q, PANG K, BROWNE W E, SMITH S A, SEAVER E, ROUSE G W, OBST M, EDGECOMBE G D, et al. (2008). Broad phylogenomic sampling improves resolution of the animal tree of life. Nature. 452: 745-749.

ESSNER J, BRANFORD W, ZHANG J and YOST H (2000). Mesendoderm and left-right brain, heart and gut development are differentially regulated by pitx2 isoforms. Development 127: 1081-1093.

FLOT J F, HESPEELS B, LI X, NOEL B, ARKHIPOVA I, DANCHIN E G J, HEJNOL A, HENRISSAT B, KOSZUL R, AURY J M, et al. (2013). Genomic evidence for ameiotic evolution in the bdelloid rotifer Adineta vaga. Nature 500: 453-457.

FREEMAN G, LUNDELIUS J W (1982). The developmental genetics of dextrality 
and sinistrality in the gastropod Lymnaea peregra. Dev Genes Evol 191: 69-83. FÜRSICH F T, PALMER T (2007). Commissural asymmetry in brachiopods. Lethaia 17: 251-265.

GHIRARDELLI E (1981). I Chaetognati: posizione sistematica, affinità ed evoluzione del phylum. Origine dei grande phyla Nazionale dei metazoi 191-233.

GIRIBET G, DISTEL D L, POLZ M, STERRER W and WHEELER W C (2000). Triploblastic relationships with emphasis on the acoelomates and the position of Gnathostomulida, Cycliophora, Plathelminthes, and Chaetognatha: a combined approach of 18S rDNA sequences and morphology. Syst Biol 49: 539-562.

GRANDE C, PATEL N H (2009). Nodal signalling is involved in left-right asymmetry in snails. Nature 457: 1007-1011.

GRANDE C (2010). Left-right asymmetries in Spiralia. Integ Comp Biol 50: 744-755.

GRANDE C, PATELN H (2010). Lophotrochozoa get into the game: the nodal pathway and left-right asymmetry in Bilateria. Cold Spring Harbor Ann Symp; evolution: the molecular landscape 74: 281-287.

GURDON J B, BOURILLOT P Y (2001). Morphogen gradient interpretation. Nature 413: 797-803

HAGOS E G, DOUGAN ST (2007). Time-dependent patterning of the mesoderm and endoderm by Nodal signals in zebrafish. BMC Dev Biol 7: 22 .

HALANYCH K M (2004). The new view of animal phylogeny. Annu Rev Ecol Evol Syst 35: 229-256.

HAMADA H, MENO C, WATANABE D and SAIJOH Y (2002). Establishment of vertebrate left-right asymmetry. Nat Rev Genet 3: 103-113.

HARZSCH S, MÜLLER C H (2007). A new look at the ventral nerve centre of Sagitta: implications for the phylogenetic position of Chaetognatha (arrow worms) and the evolution of the bilaterian nervous system. Front Zool 4: 14.

HARZSCH S, MÜLLER C H, RIEGER V, PEREZ Y, SINTONI S, SARDET C and HANSSON B (2009). Fine structure of the ventral nerve centre and interspecific identification of individual neurons in the enigmatic Chaetognatha. Zoomorphology 128: 53-73.

HARZSCH S, WANNINGER A (2010). Evolution of invertebrate nervous systems: the Chaetognatha as a case study. Acta Zoologica 91: 35-43.

HEJNOLA, MARTINDALE M Q (2009). Coordinated spatial and temporal expression of Hox genes during embryogenesis in the acoel Convolutriloba longifissura. BMC Biol 7: 65.

HEJNOL A, OBST M, STAMATAKIS A, OTT M, ROUSE G W, EDGECOMBE G D, MARTINEZ P, BAGUÑ̇̀ J, BAILLY X, JONDELIUS U, et al. (2009). Assessing the root of bilaterian animals with scalable phylogenomic methods. Proc Biol Sci 276: 4261-4270.

HELFENBEIN K G, BOORE J L (2004). The mitochondrial genome of Phoronis architecta-comparisons demonstrate that phoronids are lophotrochozoan protostomes. Mol Biol Evol 21: 153-157.

HERPIN A, LELONG C and FAVREL P (2004). Transforming growth factor- $\beta$-related proteins: an ancestral and widespread superfamily of cytokines in metazoans. Dev Comp Imm 28: 461-485.

HUANG S B, SAHEKI Y, VANHOVEN M, TORAYAMA I, ISHIHARA T, KATSURA I, VAN DER LINDEN A, SENGUPTA P and BARGMANN C I (2007). Left-right olfactory asymmetry results from antagonistic functions of voltage-activated calcium channels and the Raw repeat protein OLRN-1 in C. elegans. Neural Dev. 2: 24.

KENNY N J, NAMIGAI E K O, DEARDEN P K, HUI J H L, GRANDE C and SHIMELD S M (2014). The Lophotrochozoan TGF $\beta$ signalling cassette: diversification and conservation in a key signalling pathway. Int J Dev Biol 58: 533-549.

KONDO S, MIURAT (2010). Reaction-diffusion model as a framework for understanding biological pattern formation. Science 329: 1616-1620.

KURODA R, ENDO B, ABE M and SHIMIZU M (2009). Chiral blastomere arrangement dictates zygotic left/right asymmetry pathway in snails. Nature 462: 790-794.

LARKIN M A, BLACKSHIELDS G, BROWN N P, CHENNA R, MCGETTIGAN P A, MCWILLIAM H, VALENTIN F, WALLACE I M, WILM A, LOPEZ R, THOMPSON J D, etal. (2007). Clustal W and Clustal X version 2.0. Bioinformatics 23: 2947-2948.

LAWRENCE M G, MARGARYAN N V, LOESSNER D, COLLINS A, KERR K M, TURNER M, SEFTOR E A, STEPHENS C R, LAI J, APC BIORESOURCE, et al. (2011). Reactivation of embryonic nodal signaling is associated with tumor progression and promotes the growth of prostate cancer cells. Prostate 71: 1198-1209.

LE S Q, GASCUEL O (2008). LG: An improved, general amino-acid replacement matrix. Mol Biol Evol 25: 1307-1320.
LEE C C, JAN H J, LAI J H, MA H I, HUENG D Y, LEE Y C G, CHENG Y Y, LIU L W WEI H W and LEE H M (2010). Nodal promotes growth and invasion in human gliomas. Oncogene 29: 3110-3123.

LEVIN M, THORLINT, ROBINSON K, NOGIT and MERCOLAM (2002). Asymmetries in $\mathrm{H}+/ \mathrm{K}+-\mathrm{ATPase}$ and cell membrane potentials comprise a very early step in left-right patterning. Cell 111: 77-89.

LITTLEWOOD D T J, TELFORD M J, CLOUGH K A and ROHDE K (1998). Gnathostomulida - an enigmatic metazoan phylum from both morphological and molecular perspectives. Mol Phyl Evol 9: 72-79.

LOGAN M, PAGÁN-WESTPHAL S M, SMITH D M, PAGANESSI L and TABIN C J (1998). The transcription factor Pitx2 mediates situs-specific morphogenesis in response to left-right asymmetric signals. Cell 94: 307-317.

LONARDO E, HERMANN P C, MUELLER M T, HUBER S, BALIC A, MIRANDALORENZOI, ZAGORAC S, ALCALAS, RODRIGUEZ-ARABAOLAZAI, RAMIREZ $\mathrm{J} \mathrm{C}$, et al. (2011). Nodal/Activin signaling drives self-renewal and tumorigenicity of pancreatic cancer stem cells and provides a target for combined drug therapy. Cell Stem Cell 9: 433-446.

MADDISON W P, MADDISON D R (2011). Mesquite: a modular system for evolutionary analysis. Version $2.75 \mathrm{http}: / /$ mesquiteproject.org

MARLÉTAZ F, MARTIN E, PEREZ Y, PAPILLON D, CAUBIT X, LOWE C J, et al., (2006). Chaetognath phylogenomics: a protostome with deuterostome-like development. Curr Biol 16: R577-R578.

MARLÉTAZ F, GILLES A, CAUBIT X, PEREZ Y, DOSSAT C, SAMAIN S, GYAPAY G, WINCKER P and LE PARCO Y (2008). Chaetognath transcriptome reveals ancestral and unique features among bilaterians. Genome Biol 9: R94

MARTÍN-DURÁN J M, AMAYA E and ROMERO R (2010). Germ layer specification and axial patterning in the embryonic development of the freshwater planarian Schimdtea polychroa. Dev Biol 340: 145-158.

MASSAGUÉ J (2012). TGF $\beta$ signalling in context. Nat Rev Mol Cell Biol 13: 616-630.

MATUS D Q, COPLEY R R, DUNN C W, HEJNOL A, ECCLESTON H, HALANYCH K M, MARTINDALE M Q and TELFORD M J (2006). Broad taxon and gene sampling indicate that chaetognaths are protostomes. Curr Biol 16: R575-6.

MCINTIRE S L, GARRIGA G, WHITE J, JACOBSON D and HORVITZ R H (1992). Genes necessary for directed axonal elongation or fasciculation in $C$. elegans. Neuron 8: 307-322.

MOROKUMAJ, UENO M, KAWANISHIH, SAIGAH and NISHIDAH (2002). HrNodal, the ascidian nodal-related gene, is expressed in the left side of the epidermis, and lies upstream of HrPitx. Dev Genes Evol 212: 439-446.

NAKANO H, LUNDIN K, BOURLAT S J, TELFORD M J, FUNCH P, NYENGAARD J R, OBST M and THORNDYKE M C (2013). Xenoturbella bocki exhibits direct development with similarities to Acoelomorpha. Nat Comm 4: 1537.

NAMIGAI E K O, KENNY N J and SHIMELD S M (2014). Right across the tree of life: The evolution of left-right asymmetry in the Bilateria. genesis advanced access ahead of print: doi:10.1002/dvg.22748

NESNIDAL M P, HELMKAMPF M, MEYER A, WITEK A, BRUCHHAUS I, EBERSBERGER I, HANKELN T, LIEB B, STRUCK T H and HAUSDORF B (2013). New phylogenomic data support the monophyly of Lophophorata and an EctoproctPhoronid clade and indicate that Polyzoa and Kryptrochozoa are caused by systematic bias. BMC Evol Biol 13: 253.

OHGURO Y, TAKATA H and KOMINAMI T (2011). Involvement of Delta and Nodal signals in the specification process of five types of secondary mesenchyme cells in embryo of the sea urchin, Hemicentrotus pulcherrimus. Dev Growth Differ 53 110-123.

OLSON S A (1994). MacVector: an integrated sequence analysis program for the Macintosh. Methods Mol Biol 25: 195-201.

PANG K, RYAN J F, BAXEVANIS A D and MARTINDALE M Q (2011). Evolution of the TGF- $\beta$ signaling pathway and its potential role in the ctenophore, Mnemiopsis leidyi. PloS one 6: e24152.

PASSAMANECK Y J, FURCHHEIM N, HEJNOL A, MARTINDALE M Q and LÜTER $C$ (2011). Ciliary photoreceptors in the cerebral eyes of a protostome larva. Evo Devo 2: 6.

PETERSON K J, EERNISSE D J (2001). Animal phylogeny and the ancestry of bilaterians: inferences from morphology and $18 \mathrm{~S}$ rDNA gene sequences. Evol Dev 3: 170-205.

PHILIPPE H, BRINKMANN H, COPLEY R R, MOROZ L L, NAKANO H, POUSTKA A J, WALLBERG A, PETERSON K J and TELFORD M J (2011). Acoelomorph 


\section{C. Grande et al.}

flatworms are deuterostomes related to Xenoturbella. Nature 470: 255-258.

PONDER W F, LINDBERG D R (1997). Towards a phylogeny of gastropod molluscs: an analysis using morphological characters. Zool J Linn Soc 119: 83-265.

QUAIL D F, SIEGERS G M, JEWER M, and POSTOVIT L M (2013). Nodal signalling in embryogenesis and tumourigenesis. Int J Bioch Cell Biol 45: 885-898.

RAMBAUT A, DRUMMOND A J (2007) Tracer v1.4, Available from http://beast.bio. ed.ac.uk/Tracer

RIEGER V, PEREZ Y, MÜLLER C H, LIPKE E, SOMBKE A, HANSSON B S and HARZSCH S (2010). Immunohistochemical analysis and 3D reconstruction of the cephalic nervous system in Chaetognatha: insights into the evolution of an early bilaterian brain? Invert Biol 129: 77-104

RYANAK, BLUMBERG B, RODRIGUEZ-ESTEBAN C, YONEI-TAMURAS, TAMURA K, TSUKUI T, et al., (1998). Pitx2 determines left-right asymmetry of internal organs in vertebrates. Nature 394: 545-551.

SANTAGATA S, RESH C, HEJNOL A, MARTINDALE M $Q$ and PASSAMANECK $Y$ $J$ (2012). Development of the larval anterior neurogenic domains of Terebratalia transversa (Brachiopoda) provides insights into the diversification of larval apica organs and the spiralian nervous system. EvoDevo3:3. doi:10.1186/2041-9139-3-3.

SCHIER A F, SHEN M M (2000). Nodal signalling in vertebrate development. Nature 403: $385-389$

SCHIER A F, TALBOT W S (2005). Molecular genetics of axis formation in zebrafish. Ann Review Gen 39: 561-613.

SCHIER A F (2009). Nodal Morphogens. Cold Spring Harb Perspect Biol 1: a003459.

SHEN M M (2007). Nodal signalling: developmental roles and regulation. Development 134: 1023-1034.

SPÉDER P, ADAM G and NOSELLIS (2006). Type ID unconventional myosin controls left/right asymmetry in Drosophila. Nature 440: 803-807

SPÉDER P, PETZOLDT A, SUZANNE M and NOSELLI S (2007). Strategies to establish left/right asymmetry in vertebrates and invertebrates. Curr Opin Genet Dev, 17: 351-358.

SRIVASTAVA M, MAZZA-CURLL K L, VAN WOLFSWINKEL J C and REDDIEN P $W$ (2014). Whole-body acoel regeneration is controlled by Wnt and BMP-ADMP signaling. Curr Biol 24: 1107-1113.

STRIZZI L, HARDY K M, KIRSCHMANN D A, AHRLUND-RICHTER L and HENDRIX $\mathrm{MJ}$ (2012). Nodal expression and detection in cancer: experience and challenges. Cancer res 72: 1915-1920.

STURTEVANT A H (1923). Inheritance of direction of coiling in Limnaea. Science 58: $269-270$.

TIAN T, MENG A M (2006). Nodal signals pattern vertebrate embryos. Cell Mol Life Sci 63: 672-685

TOPCZEWSKA J M, POSTOVIT L M, MARGARYAN N V, SAM A, HESS A R, WHEATON W W, et al., (2006). Embryonic and tumorigenic pathways converge via Nodal signaling: role in melanoma aggressiveness. Nat Med 12: 925-932.

VINCENT S D, DUNN N R, HAYASHI S, NORRIS D P and ROBERTSON E J (2003). Cell fate decisions within the mouse organizer are governed by graded Nodal signals. Genes Dev 17: 1646-1662.

VORBRÜGGEN G, CONSTIEN R, ZILIAN O, WIMMER E A, DOWE G, TAUBERT $H$, NOLL M and JÄCKLE H (1997). Embryonic expression and characterization of a Ptx1 homolog in Drosophila. Mech Dev 68: 139-147.

WLIZLA M (2011). Evolution of nodal signaling in deuterostomes: insights from Saccoglossus kowalevskii. Doctoral dissertation. Chicago: University of Chicago. UMI Number: 3487671.

XU P, LIU J and DERYNCK R (2012). Post-translational regulation of TGF- $\beta$ receptor and Smad signaling. FEBS Lett 586: 1871-1884.

YU J K, HOLLAND L Z and HOLLAND N D (2002). An amphioxus nodal gene (AmphiNodal) with early symmetrical expression in the organizer and mesoderm and later asymmetrical expression associated with left-right axis formation. Evol Dev 4: 418-425.

ZHOU X, SASAKI H, LOWE L, HOGAN B L and KUEHN M R (1993). Nodal is a novel TGF $\beta$-like gene expressed in the mouse node during gastrulation. Nature 361: 543-547.

ZRZAVÝ J, MIHULKAS, KEPKA P, BEZDĚK A and TIETZD (1998). Phylogeny of the Metazoa based on morphological and $18 \mathrm{~S}$ ribosomal DNA evidence. Cladistics 14: $249-285$. 


\section{Further Related Reading, published previously in the Int. J. Dev. Biol.}

Planarian embryology in the era of comparative developmental biology

José M. Martín-Durán, Francisco Monjo and Rafael Romero

Int. J. Dev. Biol. (2012) 56: 39-48

http://dx.doi.org/10.1387/ijdb.113442jm

Evolutionary history of the Tricladida and the Platyhelminthes: an up-to-date phylogenetic and systematic account Marta Riutort, Marta Álvarez-Presas, Eva Lázaro, Eduard Solà and Jordi Paps

Int. J. Dev. Biol. (2012) 56: 5-17

http://dx.doi.org/10.1387/ijdb.113441mr

Hox and ParaHox genes in Nemertodermatida, a basal bilaterian clade

Eva Jiménez-Guri, Jordi Paps, Jordi García-Fernández and Emili Saló

Int. J. Dev. Biol. (2006) 50: 675-679

http://dx.doi.org/10.1387/ijdb.062167ej

On the origin of pattern and form in early Metazoans

Frederick W. Cummings

Int. J. Dev. Biol. (2006) 50: 193-208

http://dx.doi.org/10.1387/ijdb.052058fc

Cell lineage analysis of pattern formation in the Tubifex embryo. I. Segmentation in the mesoderm

A Goto, K Kitamura and T Shimizu

Int. J. Dev. Biol. (1999) 43: 317-327

http://dx.doi.org/10.1387/ijdb.10470648

Morphological evidence for a morphogenetic field in gastropod mollusc eggs

S E Tyler, R D Butler and S J Kimber

Int. J. Dev. Biol. (1998) 42: 79-85

http://dx.doi.org/10.1387/ijdb.9496789

Embryonic development of the shell in Biomphalaria glabrata (Say)

U Bielefeld and W Becker

Int. J. Dev. Biol. (1991) 35: 121-131

http://dx.doi.org/10.1387/ijdb.1768600

5 yr ISI Impact Factor $(2011)=2.959$
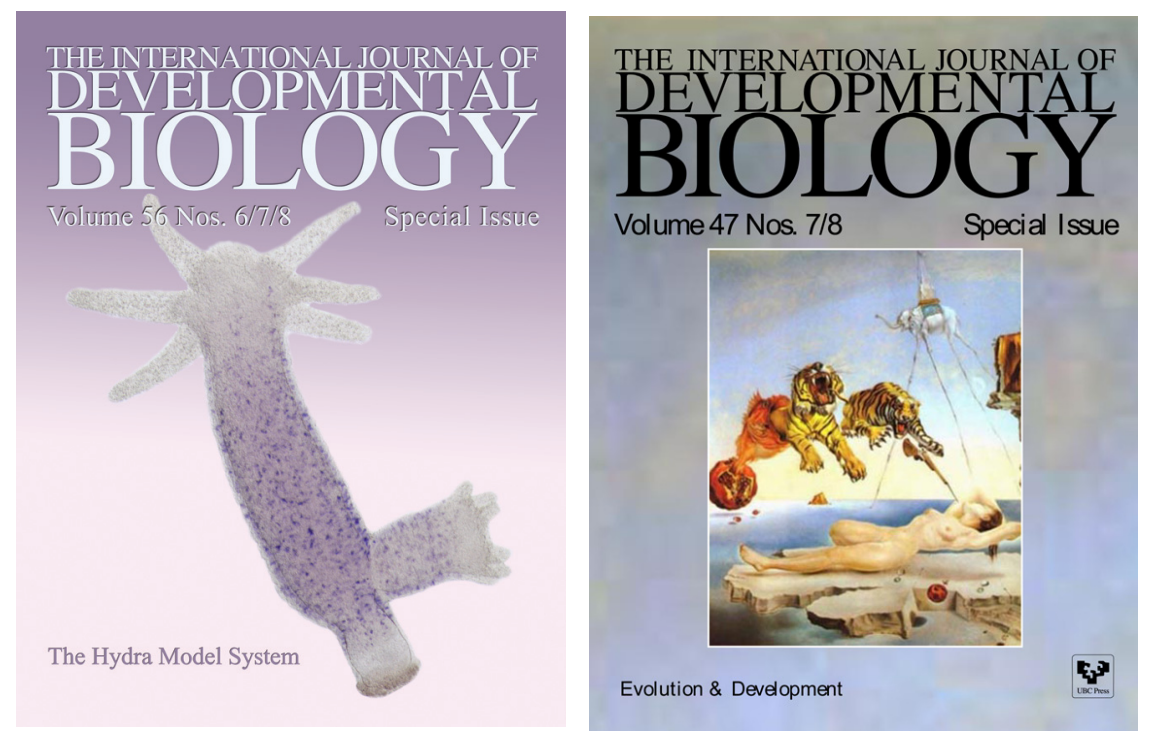

Volume 47 Nos $7 / 8$

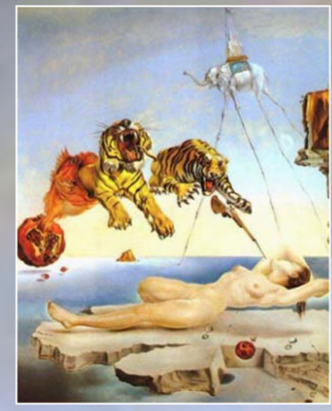

Evolution \& Development
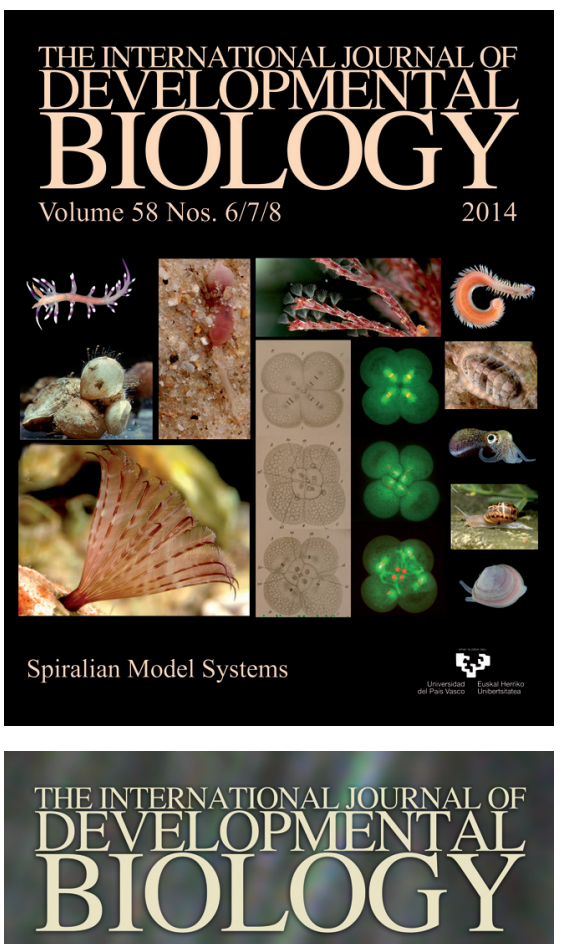

Volume 56 Nos. $1 / 2 / 3$

Special Issuc

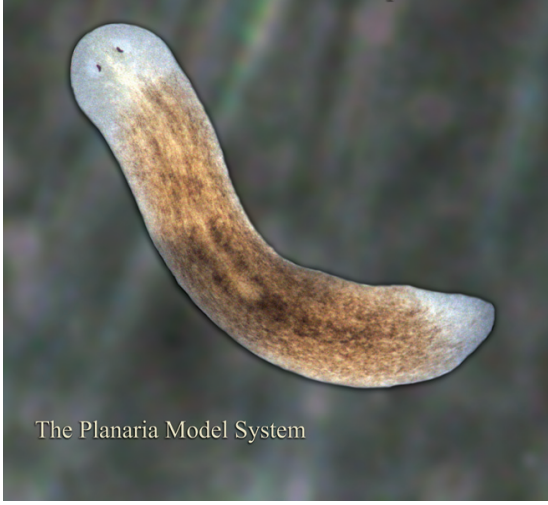

